
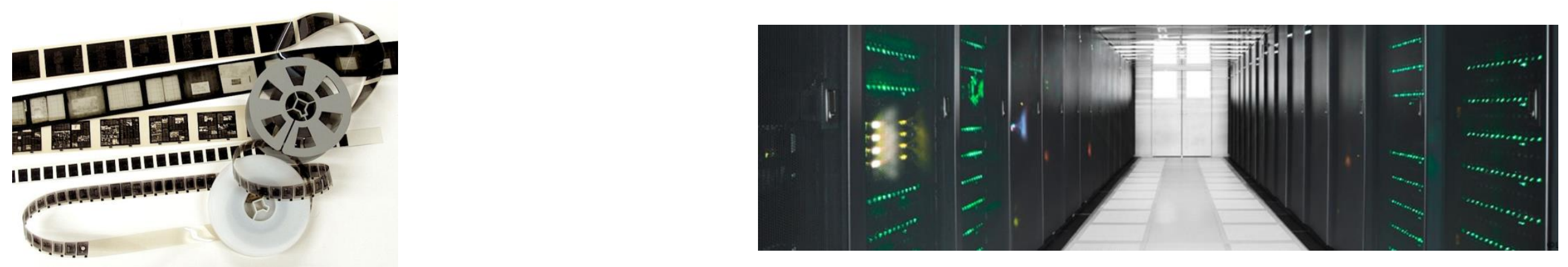

\title{
Digital vs. Analogous Long Term Preservation Microfilm still alive...?
}

\section{Michael Luetgen \\ Zeutschel Sales Manager Software Solutions \\ Kitodo Association Board Member}

\section{$\square$ SLUB}

Wir führen Wissen.
IFLA News Media Group Meeting

State and University Library, Dresden August 16 - 172017
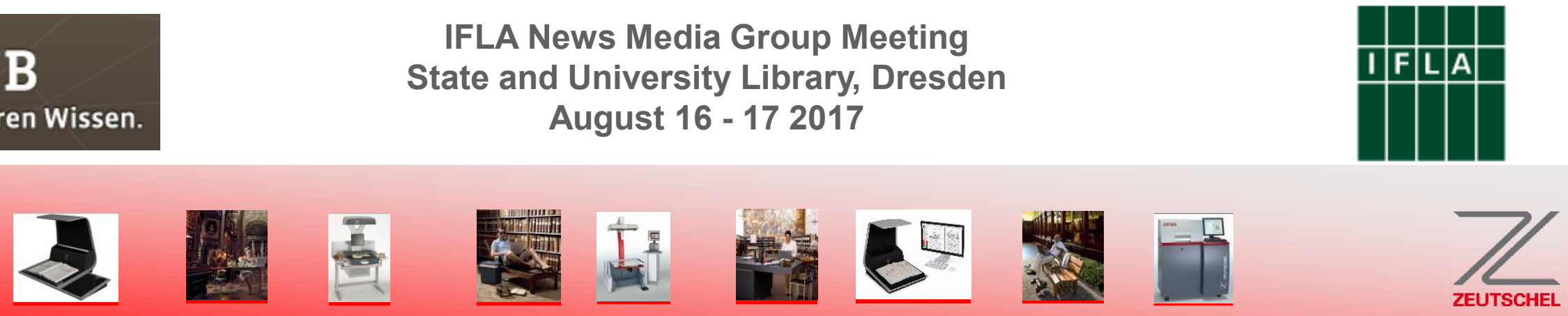


\section{Digital vs. Analogous Long Term Preservation}

- Current status of analogous Long Term Preservation (examples, standards, tendencies)

- Analogous Equipment

- Risk Management

- Cost Comparison digital vs. analogous

- Resume and practical hints

- Current status of digital Long Term Preservation 
Current status of analogous Long Term Preservation examples

Germany example Microfilming:

- State Libraries

- State Archives

- National Library

- National Archive

This situation we'll find in many countries.

Additionally Microfilming in the private Industry: Pharmacy, Chemistry etc. (Patent laws and legal evidence)

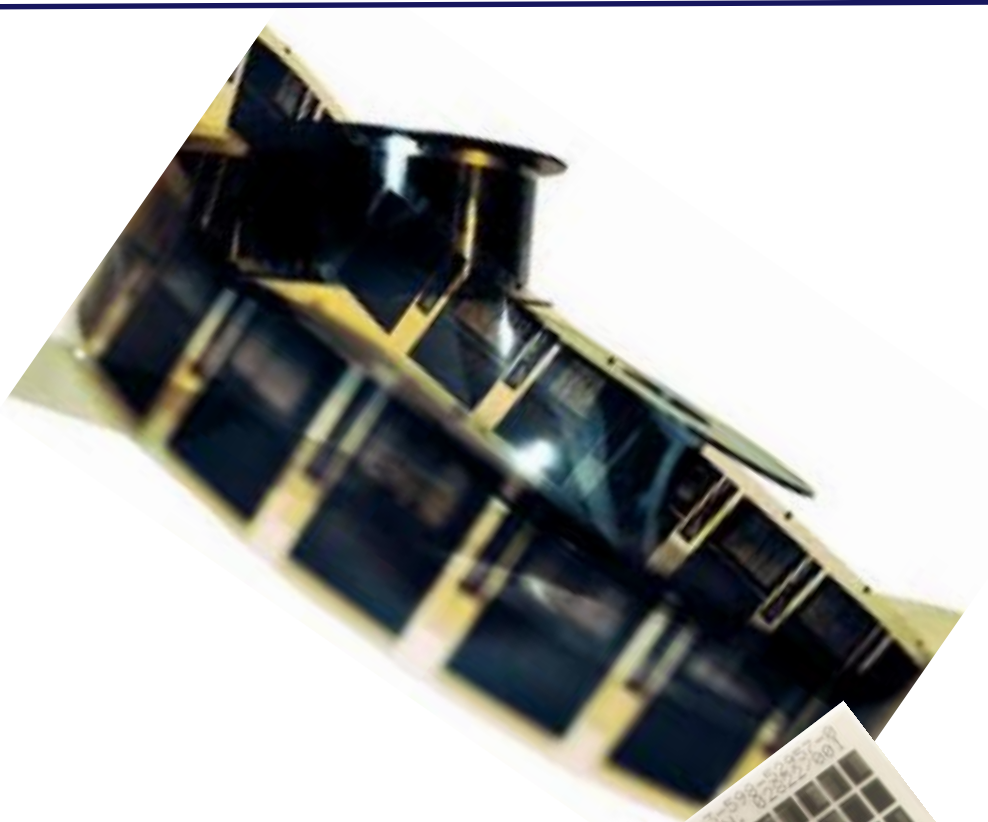




\section{Current status of analogous Long Term Preservation}

\section{standards}

Microfilm international standards are well established.

National standards in many countries are established too.

Standards helping the industry to develop the appropriated cameras, films, archive writers and reader devices.

These kinds of standards are still missing in the digital environment.
International Organization for Standardization - ISO

ISO/TR 10593:1997 - Micrographics - Use of microfilm jackets

ISO 9878:1990 - Micrographics - Graphical symbols for use in microfilming

ISO 9848:2003 - Photography - Source document microfilms - Determination of ISO speed and ISO average gradient

ISO 9378:1993 - Photography - Vesicular microfilm — Determination of ISO speed and ISO range I SO 8127-2:1999 - Micrographics - A 6 size microfilm jackets - Part 2: Other types of jacket for $16 \mathrm{~mm}$ and 35 $\mathrm{mm}$ microfilm

ISO 8127-1:1989 - Micrographics - A 6 size microfilm jackets - Part 1: Five channel jacket for $16 \mathrm{~mm}$ microfilm ISO 6148:2001 - Photography - Micrographic films, spools and cores - Dimensions (available in English only) ISO 6199:2005 - Micrographics - Microfilming of documents on $16 \mathrm{~mm}$ and $35 \mathrm{~mm}$ silver-gelatin type microfilm Operating procedures

ISO 4087:1991 - Micrographics - Microfilming of newspapers for archival purposes on $35 \mathrm{~mm}$ microfilm ISO 3272-6:2000 - Microfilming of technical drawings and other drawing office documents - Part 6: Quality criteria and control of systems for enlargements from $35 \mathrm{~mm}$ microfilm

ISO 3272-5:1999 - Microfilming of technical drawings and other drawing office documents — Part 5: Test procedures for diazo duplicating of microfilm images in aperture cards

SO 3272-4:1994 - Microfilming of technical drawings and other drawing office documents — Part 4: Microfilming of drawings of special and exceptional elongated sizes

ISO 3272-3:2001 - Microfilming of technical drawings and other drawing office documents - Part 3: Aperture card for $35 \mathrm{~mm}$ microfilm

ISO 3272-2:1994 - Microfilming of technical drawings and other drawing office documents — Part 2: Quality criteria and control of $35 \mathrm{~mm}$ silver gelatin microfilms

ISO 3272-1:2003 - Microfilming of technical drawings and other drawing office documents - Part 1: Operating rocedures

ISO 18919:1999 - Imaging materials - Thermally processed silver microfilm — Specifications for stability ISO 12650:1999 - Document imaging applications - Microfilming of achromatic maps on $35 \mathrm{~mm}$ microfilm ISO 11962:2002 - Micrographics - Image mark (blip) used with $16 \mathrm{~mm}$ and $35 \mathrm{~mm}$ roll microfilm ISO 11906:1999 - Micrographics - Microfilming of serials - Operating procedures

ISO 10198:1994 - Micrographics - Rotary camera for $16 \mathrm{~mm}$ microfilm - Mechanical and optical characteristics ISO 446:2004 - Micrographics - ISO character and ISO test chart No. 1 - Description and use (available in English only)

ISO 3334:1989 - Micrographics - ISO resolution test chart No. 2 - Description and use

ISO 3334:2006 - Micrographics - ISO resolution test chart No. 2 - Description and use

ISO 4087:1991 - Micrographics - Microfilming of newspapers for archival purposes on $35 \mathrm{~mm}$ microfilm ISO 4087:2005 - Micrographics - Microfilming of newspapers for archival purposes on $35 \mathrm{~mm}$ microfilm

ISO 6196-1:1993 - Micrographics - Vocabulary - Part 1: General terms

http://www.microfilm.net.au/useful-info/microfilm-standards/ 


\section{Analogous Equipment}

digital combination

\section{Archive Writer}

Computer Output on Microfilm From scanning back to film

\section{Microfilm Scanner}

-> self-service scanners to replace reader printer and others

-> professional devices for mass digitization

\section{Bits on Film}

Record a digital object both as image (readable to the human eye) and as bitstream (bits-on-film, computer-readable) -> needs special scan equipment

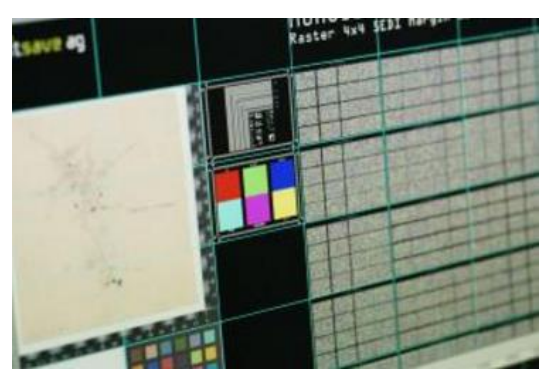

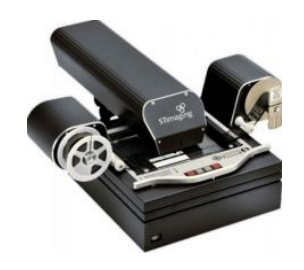

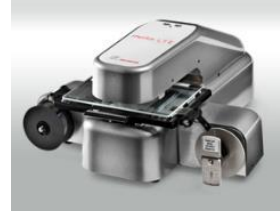

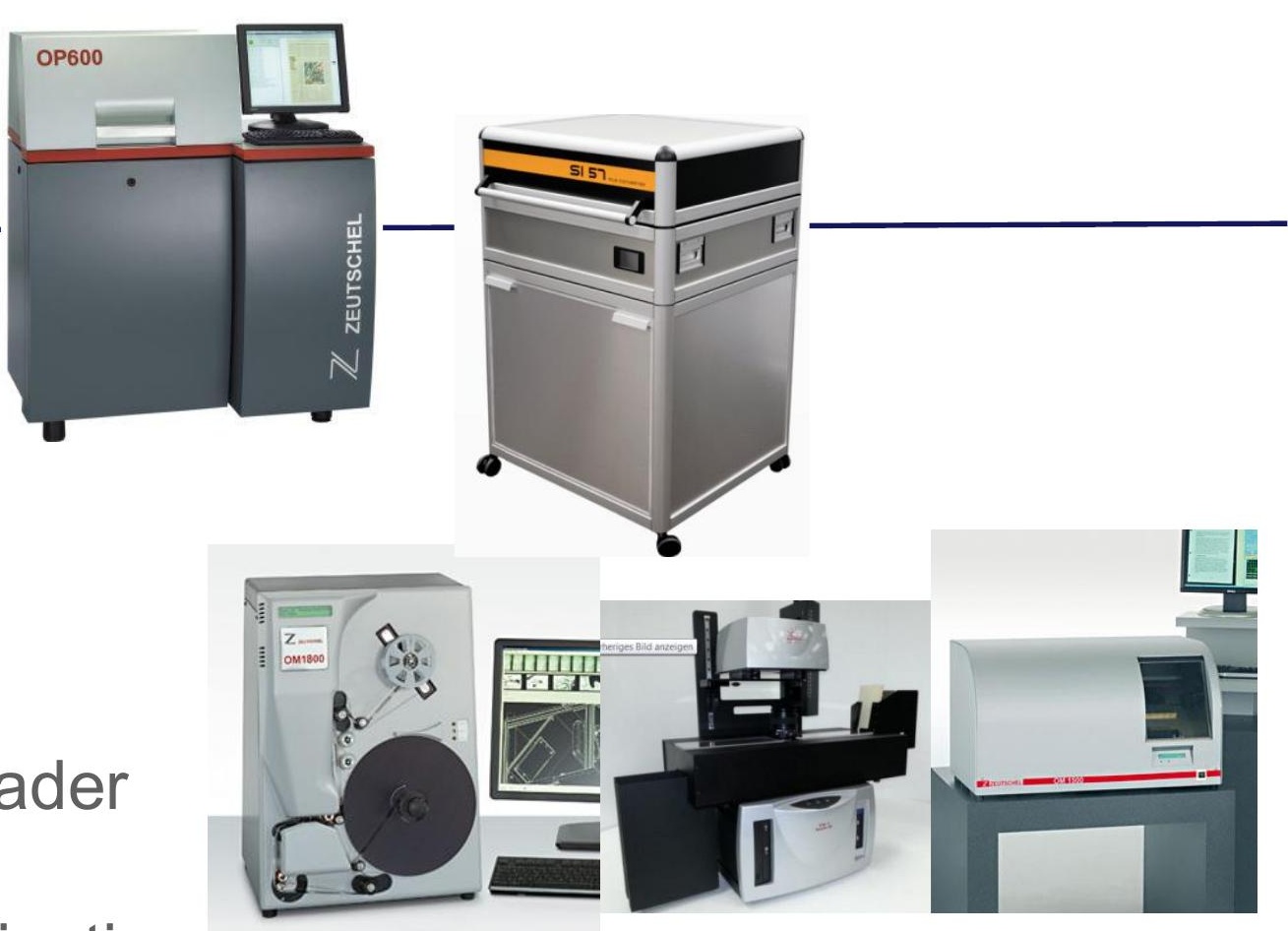




\section{Analogous Equipment market tendencies}

\section{Zeutschel experiences}

Where are we selling this equipment?

Microfilm Cameras

- Russia and Eastern Europe

- Replacements

BUT: the number of devices and revenues are not significant!

Archive Writers

- China

- Scandinavia

- Service Bureaus

Microfilm Scanner

- All around the world

Experiences from other companies are similar... 


\section{Current status of analogous Long Term Preservation}

tendencies - strategies

Why are institutions still investing in analogous technology?

\section{Germany example:}

Germany preserves all cultural goods in an old mine Barbara Stollen - on microfilm.

All State- and National Archives and State- and National Lbraries are producing and delivering.

Today the source are not only microfilm cameras but also scanners. Scanned material will be produced on microfilm (Archive Writer).

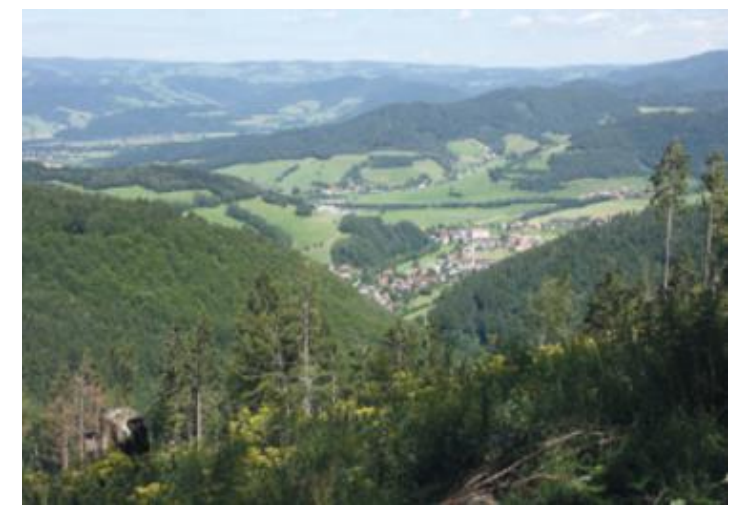

Switzerland has nearly the same strategy.

Many countries have very similar strategies.

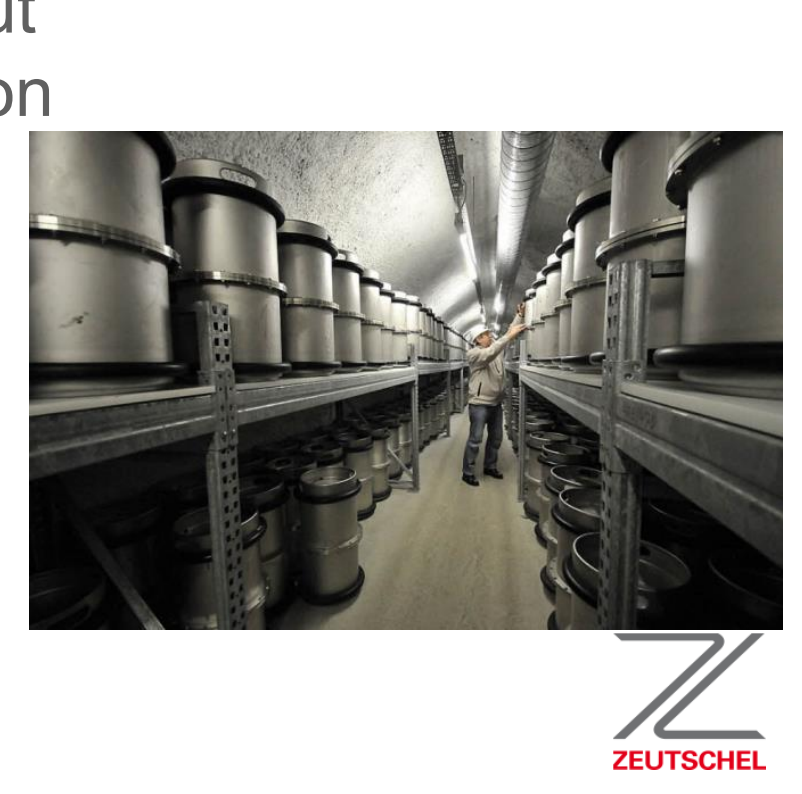

of Civil Protection and

Disaster Assistance

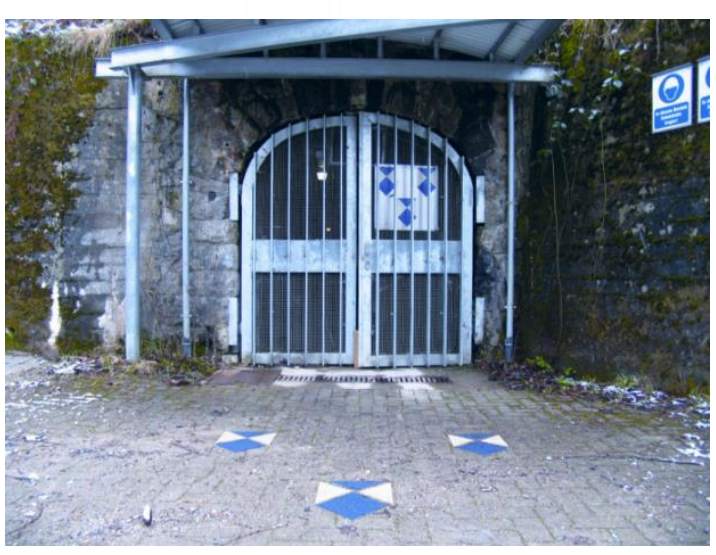




\section{Current status of analogous Long Term Preservation tendencies - strategies}

\section{Why are institutions still investing in analogous}

technology?

\section{China:}

An extended strategy...

LTP on microfilm is one case.

Production only with scanners and Archive Writers.

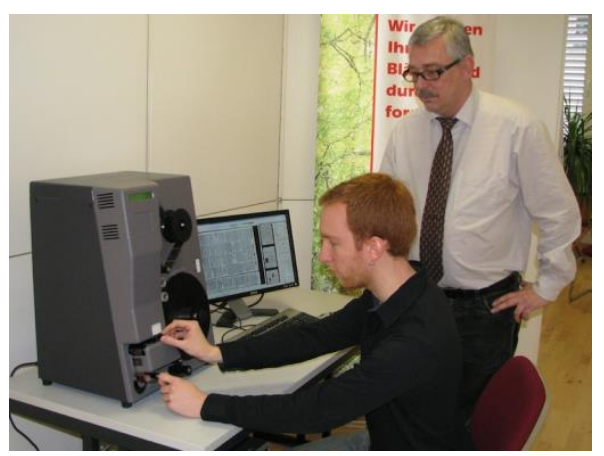

-> Digital for the information access, analogous only for LTP.

Additionally the Microfilm is an insurance also!

Scanning from Microfilm is much cheaper as from the original. In case of a digital collapse re-scanning is an alternative.

Similar procedure in Scandinavia. 


\section{Current status of analogous Long Term Preservation strategy examples}

\section{British Library}

http://www.bl.uk/aboutus/stratpolprog/collectioncare/digitalpreservation/strategy/dpstrategy.html

\section{Royal Library - The National Library of Denmark}

http://www.kb.dk/export/sites/kb dk/da/kb/downloadfiler/PreservationStrategyDigitalMaterials-KB-DK-2014.pdf

\section{LOC}

http://www.digitalpreservation.gov/about/initiatives.html\#creativeamerica

\section{DNB - German National Library}

http://www.dnb.de/DE/Service/DigitaleDienste/Digitalisierung/digitalisierungsstrategie.html

Nestor

http://www.langzeitarchivierung.de/Subsites/nestor/EN/Home/home node.html 


\section{Risk Management}

Where are the risks in the analogous technology?

\section{Equipment:}

Cameras

Microfilm shrinking market - how long the industry will support??? shrinking market - how long the industry will support??? Color microfilm production stopped some years ago.

\section{Others:}

Loosing knowledge and experience by photographers and other experts

Pollution - chemistry removal becomes a bigger problem

Access to information - microfilm is definitely not a media type for users!!!

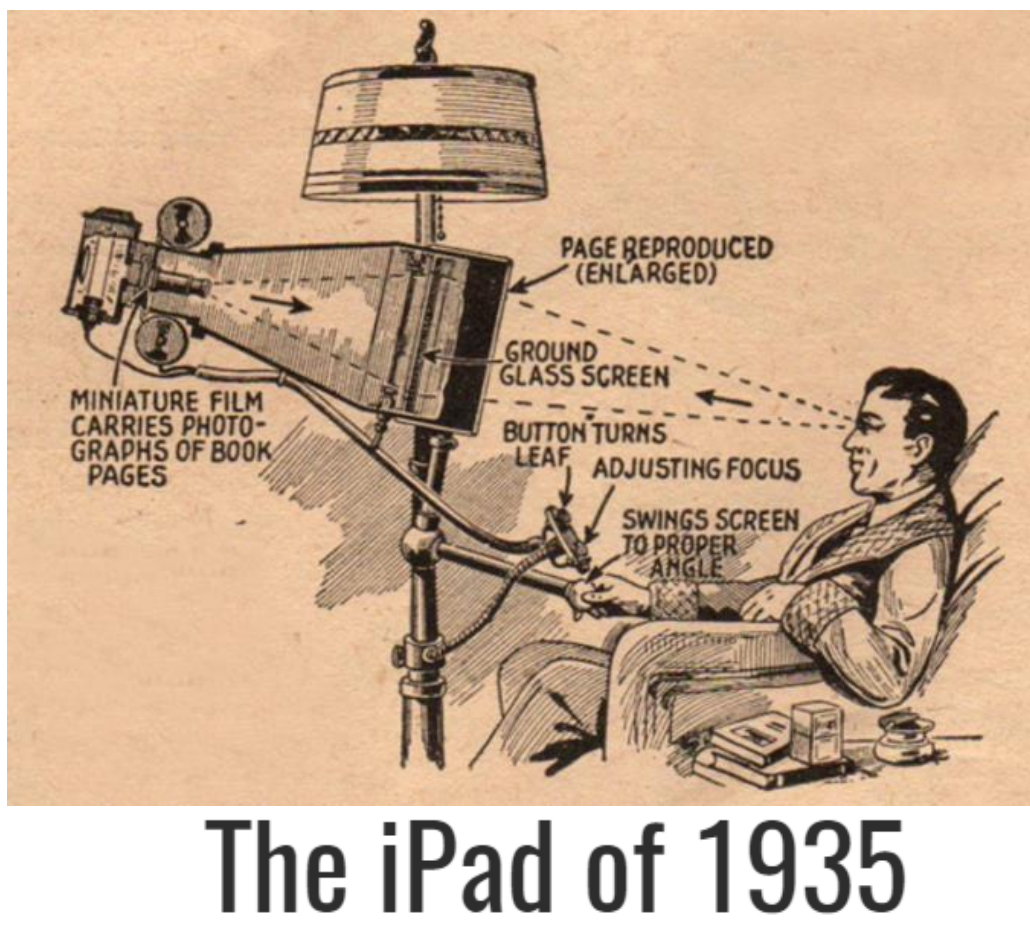




\section{Cost comparison}

In an era of digitization, NARA continues to microfilm records because microfilm is a low-cost, reliable, long-term, standardized image storage medium. The equipment needed to view microfilm images is simple, consisting of light and magnification. The medium has a life-expectancy of hundreds of years.

Digital images, on the other hand, consist of a wide variety of machine codes that require computer hardware and software to be made visible. To avoid the obsolescence of changing computer technology, digital images must be reformatted periodically.

The cost of maintaining microfilm is small compared with that of digital images. Microfilm only needs shelving in a cool, dry place for a very long period of time.

https://www.archives.gov/preservation/formats/microfilming.html 


\section{Cost comparison}

Table: Cost Comparisons of 1,000,000 Images Kept for 50 Years

\begin{tabular}{lllllll} 
Media & Equivalent & $\begin{array}{l}\text { Unit price } \\
\text { monthly }\end{array}$ & $\begin{array}{c}\text { Annual } \\
\text { Storage }\end{array}$ & $\begin{array}{l}\text { Filming/ } \\
\text { Scanning }\end{array}$ & $\begin{array}{l}\text { Total storage } \\
\text { for 50 years }\end{array}$ & Grand Total \\
\hline Microfilm & 400 reels & $\$ .04 /$ reel & $\$ 192.00$ & $\$ 42,379.50$ & $\$ 9,600.00$ & $\$ 51,979.50$ \\
\hline Paper & 500 cubic feet & $\$ .198 / \mathrm{cf}$ & $\$ 1,188.00$ & none & $\$ 59,440.00$ & $\$ 59,440.00$ \\
\hline Digital 1 & 50 gigabytes & $\$ 24.00 / \mathrm{GB}$ & $\$ 1,200.00$ & $\$ 87,000.00$ & $\$ 60,000.00$ & $\$ 147,000.00$ \\
\hline Digital 2 & $\begin{array}{l}1,000,000 \\
\text { images }\end{array}$ & $\$ .00064 /$ each & $\$ 7,680.00$ & $\$ 87,000.00$ & $\$ 384,000.00$ & $\$ 471,000.00$
\end{tabular}

Texas Record / October 25, 2010

By Jan Ferrari, Director of State and Local Records Management and State Records Administrator

https://www.tsl.texas.gov/sIrm/blog/2010/10/why-do-we-still-need-microfilm/ 


\section{Practical hints...}

\section{Microfilm is not a suitable users' medium!}

For the strategy the goals are important.

If information access is your highest priority no alternative to digitization!

BUT: the microfilm can be your insurance.

Provocation: Maybe new scanning from microfilm - in case of a digital crash - is cheaper than supporting a complete digital long term preservation environment...

If long term preservation is your highest priority and access is unimportant microfilm could be an alternative still today. Scanning from microfilm can be done on demand...

Equipment risk and dependency to vendors is fact! 
Our Disaster Recovery Plan Goes Something Like This...

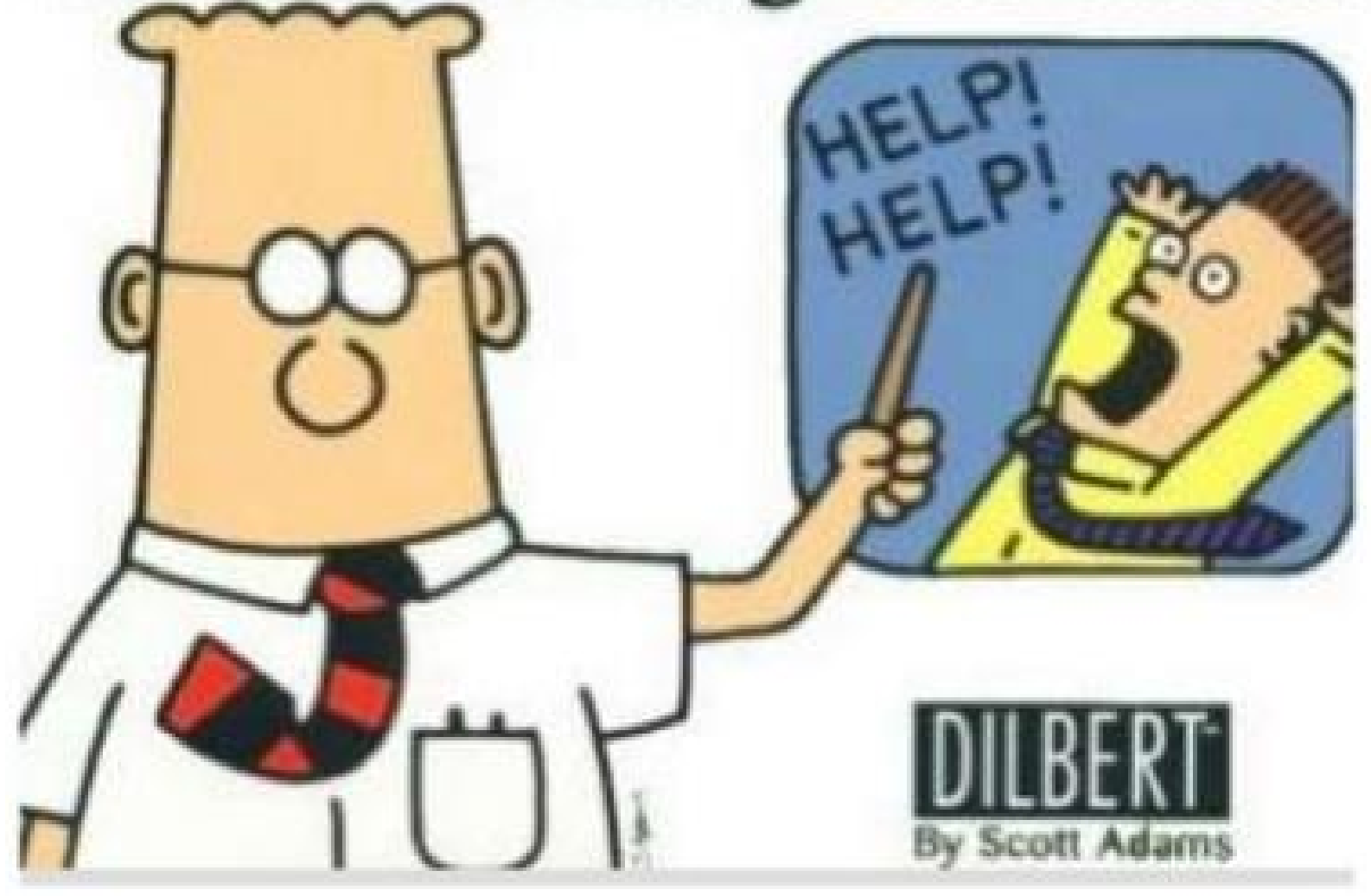

Thank you!
Questions? 